\title{
Respiratory response to BiPAP aided upper limb exercise in hypercapanic COPD patients
}

\begin{abstract}
Study design: Experimental study design

Background: Application of inspiratory support, through proportional assisted ventilation, or continuous positive airways pressure ventilation, may potentially lead to enhanced training intensity. Therapies that are aimed to enhance physical activity levels have the potential to benefit patient group. However, beneficial effects of BiPAP aided performance of upper limb activities have been poorly documented.
\end{abstract}

Purpose of the study: To investigate the beneficial effects of BiPAP aided performance of upper limb activities along with oxygen therapy in improving gas exchange, fatigue and dyspnoea in Hypercapnic COPD patients.

Method: 30 Hypercapanic COPD patients were selected for both groups. Subjects in group A performed 20 minutes upper limb activity regimen without BiPAP where as subjects in group B performed the same regimen with BiPAP. Subjects underwent ABG analysis before and immediately after intervention.

Results: Within Groups analysis showed that there was a significant rise in dyspnoea, fatigue and $\mathrm{PaCO}_{2}$ scores in both groups $(\mathrm{p}<0.001) . \mathrm{PaO}_{2}$ and $\mathrm{pH}$ scores showed significant reduction in group $\mathrm{A}$ whereas there was a significant increase in $\mathrm{PaO}_{2}$ score and a decrease in $\mathrm{pH}$ scores in group B. Between groups analysis showed significantly higher rise in dyspnoea, fatigue, $\mathrm{PaCO}_{2}$ in Group $\mathrm{A}$ as compared to that in Group $\mathrm{B}(\mathrm{p} \leq 0.05)$. $\mathrm{pH}$ scores showed significant reduction in group $A$ as compared to that in Group $B(p \leq 0.001)$.There was significantly higher rise in $\mathrm{PaO}_{2}$ score in Group $\mathrm{B}$ as compared to Group $\mathrm{A}(\mathrm{p} \leq 0.001)$.

Conclusion: The results yielded a clinically significant improvement in patients' blood gas exchange parameters and less increase in dyspnoea and fatigue in BiPAP aided Hypercapanic patients.

Keywords: BiPAP, hypercapnic, COPD, blood gas; dyspnoea
Volume 3 Issue I - 2016

\section{Saini Kirti, Sonia, Kalra Sheetal}

Dashmesh College of Physiotherapy, India

Correspondence: Kalra Sheetal, Dashmesh College of Physiotherapy, SGT group of Institutions, Gurgaon, India, Email pawaria_sonia@yahoo.co.in

Received: December 14, 2015 | Published: February 19, 2016

\section{Introduction}

Chronic Obstructive Pulmonary Disease (COPD) is a major cause of death and disability worldwide. Many people suffer from this disease for years and die prematurely of it or due to its complications. ${ }^{1}$ About three million people died worldwide due to COPDs in 2005 and WHO predicts that it will be the fourth leading cause of death world wide by $2030 .^{2}$

COPD is characterized by airflow limitation and reduced exercise capacity. Airflow limitation is usually progressive and associated with symptoms such as dyspnoea, excessive sputum production and chronic cough. ${ }^{2}$ Dyspnoea and fatigue are the two most common symptoms experienced by patients with COPD. ${ }^{3}$ While dyspnoea has been traditionally considered the primary symptom in COPD patients, recent attention to measures of fatigue have shown both dyspnoea and fatigue to be important symptoms in this population. ${ }^{4}$

COPD patients have a decreased exercise capacity and reduced activity level compared to healthy controls. ${ }^{5}$ They often complain of severe exertional dyspnoea and have limited ventilator reserve during exercise. ${ }^{6}$ The ventilation capacity further decrease with the development of acute or chronic Hypercapanic respiratory failure (HRF). ${ }^{7}$ Exercise intolerance is one of the most distressing consequences of COPD. Presence of limitation in physical activity or exercise in COPD patients is due to dyspnea. ${ }^{8}$

The upper limbs (ULs) are used extensively in daily life for carrying out activities in daily living (ADLs). As the disease progresses, the patients have thoraco abdominal asynchrony which increases the oxygen consumption and increase the minute ventilation (VE) during efforts of the ULs without support. ${ }^{9}$ Exercise training for patients with COPD has traditionally emphasized lower-extremity exercise (e.g. walking, cycling); however, many patients with COPD report disabling dyspnoea for daily activities involving the upper extremities (eg lifting, grooming) at work levels much lower than for lower extremity exercise. ${ }^{10}$

Non invasive ventilation (NIV) refers to the provision of ventilatory support through the upper airway, with the use of a face mask. Noninvasive mechanical ventilation (NIV), administered in the form of continuous positive pressure ventilation support ventilation (bi-level positive airways pressure or proportional assisted ventilation), unload the respiratory muscle. ${ }^{11}$

Hence the application of inspiratory support, through proportional assisted ventilation, or continuous positive airways pressure ventilation, may potentially lead to enhanced training intensity. So, the 
aim of present study was to investigate the beneficial effects of BiPAP aided performance of upper limb activities along with oxygen therapy in improving gas exchange, fatigue and dyspnoea in Hypercapnic COPD patients.

\section{Methods}

\section{Study design}

The study had an experimental (Pretest-Posttest) design.

\section{Subjects}

30 subjects were taken and divided into two groups:

Group A- were given upper extremity exercises and received $\mathrm{O}_{2}$ by mask.

Group B- were given upper extremity exercises and received $\mathrm{O}_{2}$ through BiPAP.

Inclusion criteria included age group 40-60years, male and female subjects, COPD patients with hypercapnia, patients having dyspnoea, patient on domiciliary oxygen therapy.

Exclusion criteria included subjects unable to tolerate $>1 \mathrm{hr}$ of BiPAP, $\mathrm{SpO}_{2}<88 \%$ with $\mathrm{FiO}_{2} \geq 0.5$; resting $\mathrm{SBP}<90$ or $>160 \mathrm{mmHg} \&$ diastolic $<60$ or $>100 \mathrm{mmHg}$, unstable angina or previous MI, resting HR $>120 /$ min, decreased sensorium.

\section{Procedure}

A written informed consent was taken from all the subjects. All the subjects selected for the study for both groups underwent initial assessment. Variables dyspnoea, fatigue and ABG parameters were evaluated before and immediately after the intervention.

\section{Intervention}

Subjects in group A performed 20minutes upper limb activity regimen without BiPAP where as subjects in group B performed the same regimen with BiPAP.

The patients in both groups were continuously monitored with respect to $\mathrm{VO}_{2}, \mathrm{VCO}_{2}$, heart rate (HR), and dyspnoea index according to the Borg scale both at rest and during the execution of the following four activities of daily living (ADLs).

i. Sweeping the floor using a broom with nylon bristles for $5 \mathrm{~min}$ on a previously determined rubber surface. The movements of the individuals during this activity was constricted to a small area due to the limited extension of the tube that connected the metabolic system to the face mask of the individual for the collection of information about the metabolic and ventilator variables.

ii. Erasing a blackboard for 5 min with the blackboard placed in front of the individual. The subject started this activity with the dominant upper limb semi-flexed at the elbow but allowed to switch arms if he becomes fatigued.

iii. Lifting pots weighing $0.5,1.0,2.0,3.0,4.0$, and $5.0 \mathrm{~kg}$ with both arms simultaneously extended in order to pick up the pots that are at waist level, and then lift them above the head and put them down on a surface at that level. The arms were then lowered without a weight, and the individual performed the opposite effort, picking up the pot above his head and putting it down at waist level. The exercise was started by lifting the lightest pot and continued with progressively heavier pots until the series get completed. The series were repeated as many times as necessary to complete $5 \mathrm{~min}$, and the number of series completed were not taken into consideration.

iv. Screwing in and out a bulb from four sockets placed at the height of the eyes, starting with the dominant arm semi-flexed at the elbow. However, switching arms during this activity was permitted depending on fatigue. This activity was performed over a period of $5 \mathrm{~min}$, and numbers of bulb changes were not taken into account.

\section{Outcome measures}

ABG parameters were measured by blood sampling. Dyspnoea and Fatigue were measured by modified borg,s scale.

\section{Result}

There was no significant difference in baseline pulmonary functions and demographics in subjects in both the groups (Table 1). Within Groups analysis showed that there was a significant rise in dyspnoea, fatigue and $\mathrm{Pa} \mathrm{CO}_{2}$ scores in both groups $(\mathrm{p}<0.001) . \mathrm{PaO}_{2}$ and $\mathrm{pH}$ scores showed significant reduction in group $\mathrm{A}$ whereas there was a significant increase in $\mathrm{PaO}_{2}$ score and a decrease in $\mathrm{pH}$ scores in group B (Table 2) (Table 3).

Between Group analysis showed significantly higher rise in dyspnoea, fatigue, $\mathrm{PaCO}_{2}$ in Group $\mathrm{A}$ as compared to that in Group $\mathrm{B}(\mathrm{p} \leq 0.05)$. $\mathrm{pH}$ scores showed significant reduction in group A as compared to that in Group B ( $\mathrm{p} \leq 0.001)$. There was significantly higher rise in $\mathrm{PaO}_{2}$ score in Group B as compared to Group A ( $\left.\mathrm{p} \leq 0.001\right)$. (Table 4).

Table I Subjects baseline characteristics represented as Mean \pm SD.

\begin{tabular}{llll}
\hline Variables & $\begin{array}{l}\text { Group A(n=15) } \\
\text { Mean } \pm \text { S.D }\end{array}$ & $\begin{array}{l}\text { Group B(n=15) } \\
\text { Mean } \pm \text { S.D }\end{array}$ & T-value \\
\hline Age (Years) & $53.20 \pm 4.02$ & $54.53 \pm 4.49$ & 0.72 INS \\
$\mathrm{BMl}(\mathrm{Kg} / \mathrm{m} 2)$ & $22.81 \pm 1.99$ & $23.27 \pm 2.17$ & $1.020 \mathrm{NS}$ \\
Gender Male/Female & $10 / 5$ & $12 / 3$ & $0.248 / 0.252 \mathrm{NS}$ \\
$\begin{array}{l}\text { Modified Borg Score } \\
\text { (Dyspnoea) }\end{array}$ & $0.867 \pm 0.640$ & $1.067 \pm 0.704$ & $0.814 \mathrm{NS}$ \\
$\begin{array}{l}\text { Modified Borg Score (Fatigue) } \\
0.800 \pm 0.676\end{array}$ & $68.320 \pm 1.307$ & $0.933 \pm 0.594$ & $0.574 \mathrm{NS}$ \\
$\mathrm{PaO}_{2}$ & $51.053 \pm 2.213$ & $69.413 \pm 4.661$ & $0.875 \mathrm{NS}$ \\
$\mathrm{PaCO}_{2}$ & & $52.027 \pm 4.860$ & $0.706 \mathrm{NS}$ \\
\hline
\end{tabular}


Table continued...

\begin{tabular}{llll}
\hline Variables & $\begin{array}{l}\text { Group A(n=I5) } \\
\text { Mean } \pm \text { S.D }\end{array}$ & $\begin{array}{l}\text { Group B(n=15) } \\
\text { Mean } \pm \text { S.D }\end{array}$ & T-value \\
\hline $\mathrm{PH}$ & $7.35 \pm 0.01$ & $7.35 \pm 0.01$ & $1.122 \mathrm{NS}$ \\
\hline
\end{tabular}

*Significant at $\mathrm{p} \leq 0.05$

$* *$ Highly significant at $\mathrm{p}<0.001$

NS, non significant

Table 2 Within Group Analysis Group A

\begin{tabular}{llll}
\hline Variables & Pre exercise Mean \pm SD & Post exercise Mean \pm SD & T- value \\
\hline Dyspnoea & $0.867 \pm 0.640$ & $2.467 \pm 0.990$ & $6.287^{* *}$ \\
Fatigue & $0.800 \pm .676$ & $1.800 \pm 0.676$ & $10.247 * *$ \\
$\mathrm{PaCO} 2$ & $51.053 \pm 2.213$ & $57.913 \pm 3.820$ & $7.936^{* *}$ \\
$\mathrm{PaO} 2$ & $68.320 \pm 1.307$ & $62.013 \pm 2.276$ & $5.205^{* *}$ \\
$\mathrm{PH}$ & $7.35 \pm 0.01$ & $7.33 \pm 0.01$ & $15.62^{* *}$ \\
\hline
\end{tabular}

*Significant at $p \leq 0.05$

**Highly significant at $\mathrm{p}<0.001$

NS, non significant

Table 3 Within Group analysis Group B

\begin{tabular}{llll}
\hline Variables & Pre exercise mean \pm SD & Post exercise mean \pm SD & T- value \\
\hline Dyspnoea & $1.067 \pm 0.704$ & $1.533 \pm 0.640$ & $2.824^{*}$ \\
Fatigue & $0.933 \pm 0.594$ & $1.400 \pm 0.507$ & $2.824^{*}$ \\
$\mathrm{PaCO} 2$ & $52.027 \pm 4.860$ & $52.253 \pm 4.982$ & $3.302^{* *}$ \\
$\mathrm{PaO} 2$ & $69.413 \pm 4.661$ & $79.747 \pm 5.049$ & $13.459^{* *}$ \\
$\mathrm{pH}$ & $7.35 \pm 0.01$ & $7.34 \pm 0.01$ & $16^{* *}$ \\
\hline
\end{tabular}

*Significant at $\mathrm{p} \leq 0.05$

**Highly significant at $\mathrm{p}<0.00 \mathrm{I}$

NS, non significant

Table 4 Between Group Analysis

\begin{tabular}{llll}
\hline Variables & Group A Mean \pm SD & Group B Mean \pm SD & T- value \\
\hline Dyspnoea & $2.467 \pm 0.990$ & $1.533 \pm 0.640$ & $2.824^{*}$ \\
Fatigue & $1.800 \pm 0.676$ & $1.400 \pm 0.507$ & $2.779^{*}$ \\
$\mathrm{PaCO} 2$ & $57.913 \pm 3.820$ & $52.253 \pm 4.982$ & $3.302^{*}$ \\
$\mathrm{PaO} 2$ & $62.013 \pm 2.276$ & $79.747 \pm 5.049$ & $6.35 I^{* *}$ \\
$\mathrm{PH}$ & $7.33 \pm 0.01$ & $7.34 \pm 0.01$ & $6.349^{* *}$ \\
\hline
\end{tabular}

*Significant at $\mathrm{p} \leq 0.05$

**Highly significant at $p<0.00$ I

NS, non significant

Citation: Kirti S, Sonia, Sheetal K. Respiratory response to BiPAP aided upper limb exercise in hypercapanic COPD patients.J Lung Pulm Respir Res. 2016;3(I):17-22. DOI: 10.15406/jlprr.2016.03.00069 


\section{Discussion}

Non invasive positive pressure ventilation has been shown to be an important adjunct to pulmonary rehabilitation in Hypercapanic severe COPD patients who complain exertional dyspnoea and show desaturation during lower limb exhaustive exercises and also during 6MWT. But the effect of NPPV in Hypercapanic severe COPD patients while performing upper limb activities of daily living has not been investigated much. So the present study was conducted to analyze the impact of NPPV via portable BiPAP on respiratory responses including arterial blood gas tension $\left(\mathrm{PaO}_{2}, \mathrm{PaCO}_{2}\right.$ and $\left.\mathrm{pH}\right)$, dyspnea and fatigue.

Unsupported arm exercise is typical of activities of daily living. Unsupported arm exercise capacity has been shown to be reduced in both COPD subjects and healthy when compared with leg exercise and supported arm exercise. ${ }^{12}$ Present study included an activity regimen that considered of sweeping, erasing the board, lifting weights and changing bulbs. Patients in both Groups A \& B performed these activities at their own rhythm (frequency and repetitions), as we wanted to measure their own respiratory responses as close as possible as to how they would do it in the real world. To avoid the effect of any confounding factors on unsupported arm exercise, oxygen therapy was given to all subjects, irrespective of the groups and was standardized to achieve $\mathrm{SaO}>92-93 \%$. The result of the present study shows that there is a significant impact of ventilator assistance via portable BiPAP, on the performance of upper limb activities in Hypercapnic COPD patients.

\section{Change in dyspnoea and fatigue}

The high values on Modified Borg scale after 20minutes of activity as seen in the both the Groups may be explained by following reasons:

i. Lifting weights required a great deal of physical effort by the patients, as it involved a wide amplitude of the upper limb movements particularly shoulder

ii. Changing bulbs is complex activity in addition to requiring the simultaneously elevated and unsupported upper limbs, it also requires a fine motor coordination of the hand

iii. The maintained unsupported and elevated positions of upper limbs throughout the execution of the task require active participation of scapular belt muscles to maintain the activity. It has been shown that activities requiring a higher level of concentration lead patients with COPD to engage in short periods of apnea during these activities and are associated with dis-synchronous breathing. ${ }^{13}$

The dyspnoea reported by all the subjects after the activity supports the literature findings that point out that performance of activities involving the upper extremity of body patients with COPD may displace the respiratory functions of scapular belt muscles to a more anti-gravitational function, increasing the work done by diaphragm and the ventilator demand due to superimposed loads of dynamic hyperinflation.

These findings are in congruence with the findings of Mc Keough et al. ${ }^{14}$ who found that unsupported arm positioning above 90 degree places the chest wall in inflated position, the rib cage is expanded by passive stretch of muscles such as pectoralis major, minor and serratus anterior increase functional residual capacity and decreases inspiratory capacity. ${ }^{14} \mathrm{O}$ ' Donnel et al. ${ }^{15}$ also explained that breathing at higher lung volumes may further restrict the ability to progressively increase tidal volume, thus indicating mechanical constraints would have contributed to ventilator constraints in severe COPD. Inspiratory muscle load would have decreased due to the effects of hyperinflation, leading to impaired contractility of diaphragm and respiratory muscles and would have contributed to fatigue, by contracting against higher loads. ${ }^{15}$

It is conceivable that sustained muscle tension decreases blood flow. The reduced arm blood flow cause muscle fatigue, thereby, shortening the length of time for any arm activity. Older studies have already shown that exercises with the arms, increase the sympathetic tone and lactate concentration, suggesting that working in a position that keeps the arm muscles under for the diaphragm muscle, blood flow may progressively decrease and approach zero at $75 \%$ of maximum trans diaphragmatic pressures.

Subjects in Group A would have reached high ventilation to accomplish their tasks and blood flow may have been "stolen" from the arm muscles and redistributed to the ventilator muscles, contributing to the fatigue of the arm muscles and expressed by the high Borg index.

However, subjects in Group B had a comparatively less increase in Modified Borg scores with a mean increase of $0.466(p<0.05)$, i.e. $43.67 \%$ for dyspnoea and $0.467(\mathrm{p}<0.05)$, i.e. $47.02 \%$ for fatigue than group A who showed mean increase in dyspnoea of $1.60(\mathrm{p}<0.001)$, i.e. $184 \%$ and fatigue by a mean of $1.00(p<0.001)$ i.e. $125.0 \%$. Our result findings are supported by a study of Andrea Rossi et al 2006 while studying the effect of PSV and other modes on simple arm elevation. PSV was found to increase in ventilation (23\%), tidal volume $(48 \%)$, reduced frequency of breathing (18\%), decrease in PEEP $(59 \%)$, diaphragmatic effort (77\%) as compared to arm elevation without PSV. ${ }^{16}$

Polkey et al., ${ }^{17}$ observed that the addition of 30minutes of BiPAP with via oro nasal mask with adjustments in the IPS and inspiratory time to optimize patient comfort during exhaustive treadmill exercises reduces the slowing of inspiratory muscle relaxation rate. ${ }^{17}$

\section{Changes in $\mathrm{PaO}_{2}, \mathrm{PaCO}_{2}$ and $\mathrm{pH}$}

Subjects in Group A who performed the activity regimen without BiPAP showed an increase in $\mathrm{PaCO}_{2}$ by a mean of $6.86(\mathrm{p}<0.001)$ i.e. $13.43 \%$, decrease in $\mathrm{PaO}_{2}$ by a mean of $6.307(\mathrm{p}<0.001)$ i. e. $9.23 \%$ and $\mathrm{pH}$ by $0.02(\mathrm{p}<0.001)$ i.e. $0.27 \%$. The findings of our study are in agreement with results of $\mathrm{O}^{\prime}$ Donell et al., ${ }^{18}$ who found increase in $\mathrm{PaCO}_{2}(71 \mathrm{~mm} \mathrm{Hg}, \mathrm{p}<0.05)$ with a strong statistical correlation between exercise induced increase in $\mathrm{PaCO}_{2}$ and simultaneous increase in dynamic end expiratory lung volume $\left(r^{2}=0.62, p<0.005\right)$ among twenty clinically stable advanced COPD with varying degree of hypoxemia. The same authors also found strong co-relation between exercise arterial oxygen desaturation \& exercise induced change in $\mathrm{CO}$ production which primarily reflects worsening of alveolar hyperventilation as a result of dynamic mechanical restriction. ${ }^{18}$

Based on the above discussed research findings, it can be suggested that unsupported arm exercises result in dynamic hyperinflation or increases end expiratory lung volume which alters the breathing pattern, expansion of dead space ventilation \& reduction of $\mathrm{CO}_{2}$ elimination. The development of acute dynamic hyperinflation increases inspiratory muscle load, either due to inspiratory muscle 
fatigue, thereby, contributing to ineffective $\mathrm{CO}_{2}$ elimination produced from the whole body and thus worsening gas exchange.

Increase in $\mathrm{PaCO}_{2}$, in already Hypercapnic COPD patients may lead to further abnormal physiological mechanisms. But upper limb activities are necessary to perform the activities of daily living. To augment the unsupported arm exercise capacity, we used noninvasive positive pressure ventilation via portable BiPAP by alleviating the abnormal respiratory response.

In Group $\mathrm{B} \mathrm{PaCO}_{2}$ markedly decreased by a mean of $0.223(\mathrm{p}<0.05)$ i.e. $0.42 \%, \mathrm{PaO}_{2}$ substantially increased by a mean of $10.33(\mathrm{p}<0.001)$ i.e. $14.88 \%$ and $\mathrm{pH}$ increased by a mean of $0.01(\mathrm{p}<0.001)$ i.e. $0.14 \%$. When BiPAP with IPAP of 8-18 $\mathrm{cm} \mathrm{H}_{2} \mathrm{O}$ and EPAP of 4-6 $\mathrm{cm} \mathrm{H}_{2} \mathrm{O}$ was added to supplemental oxygen during the activity regimen.

During exercise in Hypercapnics COPD, alveolar ventilation is inadequate in relation to $\mathrm{CO}_{2}$ production. The decrease in $\mathrm{PaCO}_{2}$ in Group B would have occurred due to increase in overall minute ventilation, or alternatively, improvement in ventilation perfusion relationships.

Brochard et al. ${ }^{19}$ found a good correlation between the reduction in respiratory muscles activity due to IPS and on other hand, the lower $\mathrm{VO}_{2}$ of contracting ventilator muscles. ${ }^{19}$

Duiverman et al. ${ }^{20}$ augmented with these findings, showing the improvement in fatigue domin of CRQ score, MRF-28 total score and MRF-28 cognition score and daytime $\mathrm{PaCO}_{2}$ after noncturnal application of BiPAP with exercise training for four weeks in comparison to exercise training alone in total population of 72 , Hypercapanic severe COPD patients. ${ }^{20}$

Based on the above evidences, we can conclude that workload is reduced by unloading of respiratory muscles with the application of BiPAP for 20minutes which would have further contributed in reduction of fatigue. NPPV reduces breathlessness and allows a better limb exercise by redistribution of blood flow from the respiratory to skeletal muscles.

\section{Limitations}

a. Sample was small.

b. The results of the study were subjected to patient's effort and motivational factor.

c. Study duration was short.

d. Due to unavailability of resources, it was not possible to continue the monitoring of arterial blood gas perimeters after study design.

\section{Relevance to clinical practice}

The finding of the present study suggested to have important clinical implication. It was found that institution of BiPAP with individualized prescription during activity program resulted into elevation of dyspnoea and fatigue scores.

Institution of BiPEP during daily activities of upper limb, can be practiced in addition to other interventions to improve exercise capacity in the pulmonary rehabilitation program in addition to its use while at rest or during the sleep.

\section{Future research}

It is needed to evaluate the effects if BiPAP on other physiological variables such as minute ventilation $\left(\mathrm{V}_{\mathrm{E}}^{\circ}\right)$, Breathing Frequency $\left(\mathrm{B}_{\mathrm{f}}\right)$, after performing activities of daily living in Hypercapanic patients.

Future studies are also needed to address the impact of skeleton muscle impairment and should include subgroup analysis in order to identify patients who benefits from BiPAP after activities of daily living compared with those who do not.

Future studies should address the impact of BiPAP during different types of activities like stair climbing in Hypercapanic COPD patients.

\section{Conclusion}

The results obtained from this study in patients with Hypercapanic stable COPD, a 20minute BiPAP aided upper limb activity program yielded a clinically significant improvement in patients' blood gas exchange parameters and less increase in dyspnoea and fatigue Moreover, this improvement was significantly higher than the patients receiving only oxygen supplementation. Hence research hypothesis i.e. the use of BiPAP during upper limb activities has a significant impact on the respiratory responses in stable Hypercapanic COPD patients has been accepted.

\section{Acknowledgements}

None.

\section{Conflict of interest}

The author declares no conflict of interest.

\section{References}

1. Rabe KF, Hurd S, Anzueto A, et al. Global strategy for the diagnosis, management, and prevention of chronic obstructive pulmonary disease:GOLD executive summary. Am J Respir Crit Care Med. 2007;176(6):532-555.

2. Lau KS, Jones AY. A single session of Acu-TENS increases FEV1 and reduces dyspnoea in patients with chronic obstructive pulmonary disease:a randomised, placebo-controlled trial. Aust J Physiother. 2008;54(3):179-184.

3. Tödt K, Skargren E, Kentson M, et al. Experience of fatigue, and its relationship to physical capacity and disease severity in men and women with COPD. Int J Chron Obstruct Pulmon Dis. 2014;9:17-25.

4. Paula M, Meek RN, Suzanne C, Lareau RN. Critical outcomes in pulmonary rehabilitation: Assessment and evaluation of dyspnea and fatigue. Journal of Rehab R\&D. 2003;40(5):13-24.

5. Schonhofer B, Zimmermann C, Abramek P, et al. Non-invasive mechanical ventilation improves walking distance but not quadriceps strength in chronic respiratory failure. Respir Med. 2003;97(7):818-824.

6. Montes de Oca M, Celli BR. Respiratory muscle recruitment and exercise performance in eucapnic and hypercapnic severe chronic obstructive pulmonary disease. Am J Respir Crit Care Med. 2000;161(3-1):880885.

7. Purro A, Appendini L, Polillo C, et al. Mechanical determinants of early acute ventilatory failure in COPD patients:a physiologic study. Intensive Care Med. 2009;35(4):639-647.

8. Conti G, Rocco M, Antonelli M, et al. Respiratory system mechanics in the early phase of acute respiratory failure due to severe kyphoscoliosis. Intensive Care Med. 1997;23(5):539-544.

9. Castro AA, Porto EF, Feltrim MI, et al. Asynchrony and hyperinflation in patients with chronic obstructive pulmonary disease during two types of upper limbs exercise. Arch Bronconeumol. 2013;49(6):241-248. 
10. Ries AL, Ellis B, Hawkins RW. Upper extremity exercise training in chronic obstructive pulmonary disease. Chest. 1998;93(4):688-692.

11. Vanpee D, El Khawand C, Rousseau L, et al. Does inspiratory behaviour affect the efficiency of non-invasive ventilation in COPD patients? Respir Med. 2002;96(9):709-715.

12. Donnell DEO, Laveneziana P. Physiology and consequence of lung hyperinflation in COPD. European Respiratory Review. 2006;15(100):61-67.

13. Celi BR, Rassulo J, Make BJ. Dyssynchrounous breathing during arm but not leg exercises in patients with chronic airflow obstruction. $N$ Eng J Med. 1986;314(23):1485-1490.

14. McKeough ZJ, Alison JA, Bye PT. Arm positioning alters lung volumes in subjects with COPD and healthy subject. Aust J Physiother. 2003;49(2):133-137.

15. O'Donnell DE, D'Arsigny C, Webb KA. Effects of hyperoxia on ventilator limitation during exercise in advanced Chronic Obstructive Pulmonary Disease. Am J Respir Crit Care Med. 2001;163(4):892-898.
16. Poggi R, Appendini L, Polese G, et al. Noninvasive proportional assist ventilation during arm elevation in patients with chronic respiratory failure. A preliminary, physiologic study. Respir Med. 2006;100(6):972979.

17. Polkey MI, Kyroussis D, Mills GH, et al. Inspiratory pressure support reduces slowing of inspiratory muscle relaxation rate during exhaustive treadmill walking in severe COPD. Am Res $J$ Crit Med. 1996;154(4):1146-1150.

18. O’Donnell DE, D'Arsigny C, Fitzpatrick M, et al. Exercise hypercapnia in advanced COPD. The role of lung hyperinflation. Am J Respir Crit Care Med. 2002;166(5):663-668.

19. Brochard L, Harf A, Lorino H, et al. Inspiratory pressure support prevents diaphragmatic fatigue during weaning from mechanical ventilation. Am Rev Respir Dis. 1989;139(2):513-521.

20. Duiverman ML, Wempe JB, Bladder G, et al. Nocturnal noninvasive ventilation in addition to rehabilitation in hypercapnic patients with COPD. Thorax. 2008;63(12):1052-1057. 